\title{
AC 2007-898: STUDENT VOICES: THE RESPONSE TO A WEB-BASED LEARNING AND ASSESSMENT TOOL IN ELECTRICAL ENGINEERING
}

\section{Chris Smaill, University of Auckland}

CHRIS SMAILL holds a Ph.D. in engineering education from Curtin University of Technology, Australia, and degrees in physics, mathematics and philosophy from the University of Auckland, New Zealand. For 27 years he taught physics and mathematics at high school level, most recently as Head of Physics at New Zealand's largest secondary school. Since the start of 2002 he has lectured in the Department of Electrical \& Computer Engineering at The University of Auckland, New Zealand. 


\title{
Student Voices: the Response to a Web-based Learning and Assessment Tool in Electrical Engineering
}

\begin{abstract}
Increasing class sizes make it harder to provide students with effective skills practice, assessment and timely feedback. Computers and the Internet can help solve this problem, and to this end a Web-based tool, OASIS (Online Assessment System with Integrated Study), was developed. OASIS delivers individualized practice and assessment tasks, marks student responses, supplies prompt feedback, and logs student activity. Although the software was created to manage increasing workloads, it also appeared to be enhancing student learning. Consequently, in 2002, an action-research program was initiated that had two aims. The first aim was to develop and implement OASIS so as to best support student learning. The second aim was to confirm that OASIS did enhance student learning and to investigate the extent to which learning was enhanced. The research program involved the analysis of an extensive body of data collected by the software itself, course surveys, written responses from both present and past students, and recorded interviews with both instructors and students. The data show that students found OASIS easy to use and judged it helped them improve their skills and understanding. Instructors also noted a clear lift in student achievement. The research findings have led to ongoing, informed modifications in the software, its implementation, and teaching and assessment practices.
\end{abstract}

\section{Introduction}

Forty years ago, in the UK, the average lecture audience size was $19^{1}$, while the average discussion group size was just four ${ }^{2}$. By contrast, present-day University course sizes of two hundred or more are routine. Funding has not increased sufficiently to match this increase in student numbers ${ }^{3,4}$. Consequently there has been a significant increase in instructor workload, one that threatens the quality of education.

Assessment takes an increasing percentage of instructor resources as course sizes grow. It has been suggested ${ }^{5}$ that for courses of more than 100 students, preparing and marking just the final examination requires more instructor time than all teaching duties combined: lecturing, lecture preparation, tutorials, etc. In the author's own department, for a year-two course of 200 students, the lecturer's time was allocated $65 \%$ to assessment and $35 \%$ to lecture preparation and delivery. For a year-one course of 600 students, the corresponding figures were $78 \%$ and $22 \%$. As course sizes grow, it is clear that the area of assessment provides the best opportunity for workload reduction. However, reduced assessment is likely to be matched by reduced student effort: assessment largely determines how students approach their learning, what they focus on, and how much effort they make ${ }^{6-8}$. Reduced assessment also entails less feedback, and less-timely feedback, to students. Yet prompt feedback is of critical importance ${ }^{9-11}$. One landmark study asserted: "formative assessment is an essential component of classroom work... We know of no other way of raising standards for which such a strong prima facie case can be made" ${ }^{12}$. Overall, the research literature presents an overwhelming case for providing students with regular assessment and prompt feedback. Thus we are faced with a dilemma: while spiraling class sizes make a reduction in assessment attractive, the reality is that reduced assessment is almost certain to reduce student learning. 
Computers can provide a way to maintain effective assessment as course sizes increase. In the year following the introduction of computer-based examinations at the University of Luton, the average saving in academic staff time was $50 \%$. Subsequent years brought a further $50 \%$ saving ${ }^{13}$. Computers can also provide students with opportunities to practice their skills informally and receive prompt feedback without significantly increasing instructor workload. These opportunities can be made available to students whenever and wherever they have Internet access, thus enabling students to learn by trial and error without penalty or loss of face ${ }^{14}$ : "the greatest value of computers is that they will watch out for you and let you do stuff without fear of embarrassment" ${ }^{15}$.

Further reasons have been advanced ${ }^{16}$ for the adoption of computer-assisted assessment (CAA): to broaden the range of knowledge and skills assessed, to increase the promptness and quality of feedback to students and lecturers, to extend the range of assessment methods, to increase objectivity and consistency, and to aid administrative efficiency. CAA also enables institutions to increase the frequency of formative assessment. Institutions that have used CAA in this way have subsequently reported significant lifts in student academic achievement ${ }^{13,17-22}$.

\section{The research program}

The Department of Electrical and Computer Engineering at the University of Auckland saw computers as providing the best opportunity to maintain effective assessment and regular, timely feedback in the face of increasing workloads. Partly for reasons of cost, and partly because of perceived deficiencies in packages available at the time, the Department produced its own software package, OASIS (Online Assessment System with Integrated Study), described in the next section.

Only a prototype version of OASIS existed in 2002. This software package was wellregarded by the instructors using it, who saw it as both reducing their workload and lifting student achievement, and the decision was made to develop it further. This development was informed by an action-research program, conducted by the author over a four-year period. The research program had two aims. The first aim was to develop and implement OASIS so as to best support student learning. The second aim was to confirm that OASIS did enhance student learning and to investigate the extent to which learning was enhanced.

Action research was chosen as the most appropriate form of research since the author, as both researcher and instructor, aimed to both study the learning environment and improve materially the situation of those immersed in it ${ }^{23-26}$. If only the first aim had been important, then a different research methodology might have been adopted. It would have been very easy to simply divide the students in a course into two equivalent groups and provide one group with access to OASIS while denying the other group access. A comparison of the performances of the two groups in tests and the final examination would then have given a useful quantitative indication of the worth of OASIS. However, as there was already significant anecdotal evidence suggesting that OASIS was enhancing student learning, it would have been unethical to arbitrarily deny OASIS access to half the students on a course. Any instructor taking this step would have felt guilty about the strong possibility of disadvantaging half the students, and the students themselves certainly would have felt disadvantaged and would have complained vociferously! The fact that changes were regularly implemented in order to benefit the students also moved the research further from the traditional mathematical-sciences research model. Replicability was sacrificed in favor of 
responsiveness. Students and instructors were treated as participants and benefactors rather than objects.

In general, each semester corresponded to one cycle of action research. Each cycle involved planning changes, implementing the changes, collecting data on the results, and reflecting on the data ${ }^{27,28}$. The notion that research must be based entirely on quantitative data lost credibility some time ago ${ }^{23,29-31}$, and to maximize triangulation a wealth of both qualitative and quantitative data was gathered from a variety of sources over a four-year period. Only a fraction of the data is presented here. This fraction should be viewed not as anecdotal but as representative of a much larger body of data. Data were collected directly by OASIS, as well as by course surveys, interviews with instructors and past and present students, informal conversations and email exchanges. Permission for the research was formally obtained from both the University itself and interviewees. All interviews were recorded, transcribed and analyzed. The software package $\mathrm{N}^{32}$ was used for this analysis.

Initially, the research program focussed on re-writing the software. The prototype (written in PHP and using a MySQL database) had developed in an ad-hoc way and could not be readily modified to handle the increased demands being placed on it. This prototype was replaced with a new version of the software (written in Python and using a PostgreSQL database). Subsequently, the focus of the research program shifted to the implementation of the software itself and to the enhancement of student learning, and it is these matters that are the main subject of this paper. Of course, as a result of the research findings, the software did continue to be modified and improved on a regular basis. The following section describes the software package, while subsequent sections present some of the research program's findings.

\section{Oasis: Online Assessment System with Integrated Study}

OASIS comprises a large question database and server-side program. OASIS delivers questions to students, marks their responses, provides instant feedback, and records all student activities, including time logged on, time taken, questions attempted, answers submitted, and the correct answers to attempted questions. Because the Web server carries out all processing, students need only a computer with Internet access and a standard browser, making OASIS well suited to student-centered and large-class learning.

Students are encouraged to practice OASIS questions from day one. In this way they can improve their skills and understanding and receive timely feedback on their progress through the semester. Each question has 200 to 300 numerically different variations, so students can practice each question until satisfied they have mastered the particular skill, situation, or concept. As students practice and improve their skills, they also become familiar with the environment that will be used for assessments. Figure 1 shows a typical question from the year-two course 'Circuits \& Systems'. 


\section{Oasis}

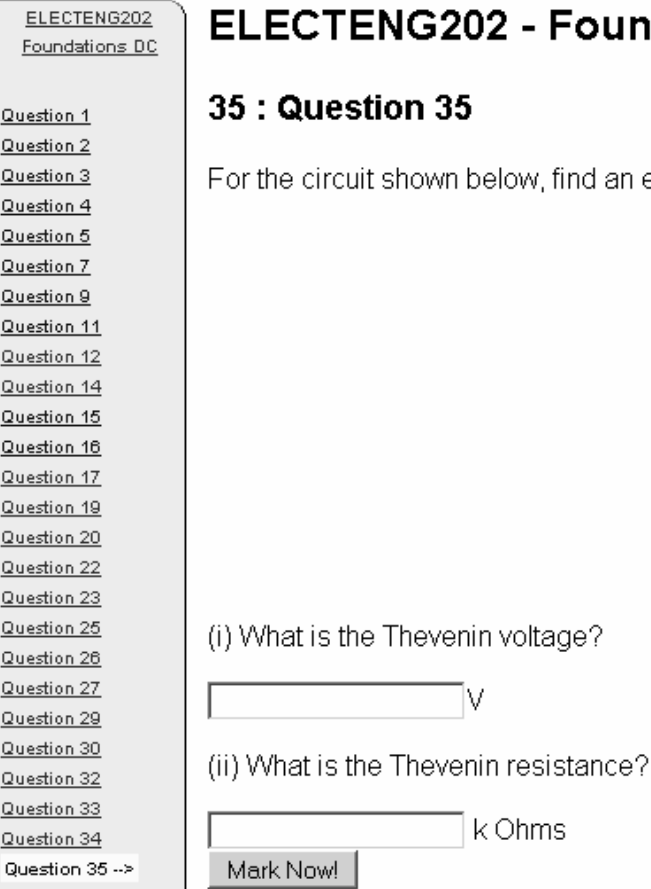

Figure 1: OASIS question from Circuits \& Systems.

The record of student activities maintained by OASIS also enables instructors to gauge progress and skills at both the course and the individual level. For example, instructors can identify at-risk students, who may reveal themselves through a lack of practice activity, a tendency to practice only immediately prior to assessments, or a high failure rate on attempted questions. Timely remedial action can then be taken to assist these poorlyperforming students. Instructors can also identify questions that students find difficult. In some cases instructors may wish to address these questions in lectures or tutorials.

Most questions involving circuits are based on a fixed circuit configuration with variable component values. In a minority of cases, slightly different circuit configurations exist within a single question. The answers for all variations of each question are already stored in the question database. Consequently, marking generally involves comparison rather than calculation and poses only a minimal load on the computer. However, some multi-part questions are marked consequentially. The current server, a $1.8 \mathrm{GHz}$ Opteron with $1 \mathrm{~GB}$ RAM, can handle more than 1000 users concurrently without loading problems. This large number can occur if, for example, one course is taking a test while another is completing an assignment and other students are practicing questions.

By default, an answer within $1 \%$ of the actual answer is deemed correct; however this tolerance can be adjusted for each question as appropriate. Figure 2 illustrates a typical screen display after a student submits his or her answers to the question shown in Figure 1. For most questions, the comment is restricted to correct or incorrect. However, a few questions have 
been written for which common errors are trapped; for these questions the comment can include feedback in which the error is identified.

For tests, candidates log on at the same time in a supervised environment. The fact that numerically different versions of the same questions are used makes cheating extremely difficult. Only the first submissions of students are marked; this prevents students submitting their answers, seeing the correct answers, and then using the 'back button' on their browsers to resubmit the correct answers. However, students can enter and revise all their answers as often as they like before actually submitting them. It is important that computerized tests offer the same flexibility as traditional written tests in this regard ${ }^{33}$. OASIS actually records all student answers; even those entered on the screen but not submitted. This function is appreciated by students whose computers have crashed part-way through a test prior to answer submission. Remaining time is displayed throughout the test; when the time expires, the student is automatically logged off.

\begin{tabular}{|c|c|c|c|c|c|c|}
\hline$\frac{\text { ELECTENG202 }}{\text { Foundetion DC }}$ & \multicolumn{6}{|c|}{ ELECTENG202 - Foundations DC } \\
\hline Question 1 & \multirow{2}{*}{\multicolumn{6}{|c|}{35 : Question 35}} \\
\hline Question 2 & & & & & & \\
\hline$\underline{Q \text { Question } 3}$ & \multicolumn{6}{|c|}{ Aarks Comment } \\
\hline $\begin{array}{l}\text { Question } 4 \\
\text { Question } 5\end{array}$ & 1 & 1.9 & 1.9 & $1 \%$ & 1.0 & Correct \\
\hline Question 7 & 2 & 14.2 & 14.24 & $1 \%$ & 1.0 & Correct \\
\hline$\frac{\frac{\text { Question 9 }}{\text { Question 11 }}}{\text { Question 12 }}$ & & & & & Tot & \\
\hline
\end{tabular}

Figure 2: OASIS response to student answer submission.

Some courses are too large to be assessed by tests as described above: there are simply insufficient computers. Assignments may be used to assess such courses. Assignments are similar to tests but are unsupervised, can be taken by students wherever they have Internet access, and have a less stringent time constraint. Normally, students are required to complete an assignment in a single one-hour period within a twelve-hour period: one hour after logging on, the assignment is closed to the student. However, a student can change computers within the hour. A seven-question assignment is illustrated in Figure 3. 


\section{Oasis}

Assignment One

Go To: Question 1 Question 2 Question 3 Question 4 Question 5 Question 6 Question 7

\section{Question 6}

An oscilloscope is used to examine the line-to-neutral voltage in a 3-phase power system

The graph below depicts what is seen on the oscilloscope screen.

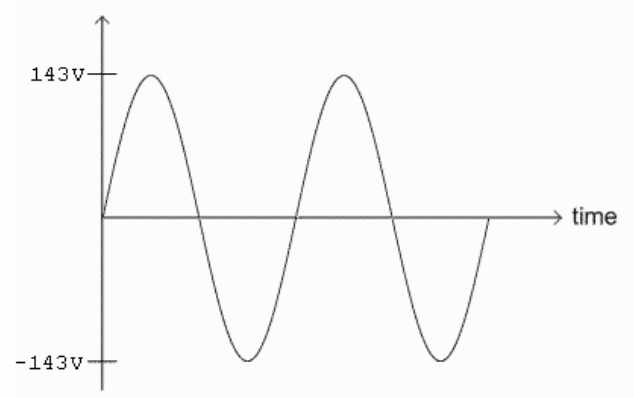

Find the value of the line-to-line voltage for this 3-phase power system

Go To: Question 1 Question 2 Question 3 Question 4 Question 5 Question 6 Question 7

NOTE: Please answer all the questions by selecting each before submitting the assessment

Submit Answers!

Figure 3: An OASIS assignment comprising seven questions.

\section{The Instructor Response to Oasis}

Since 2002, the number of courses in which OASIS is used has risen steadily. In 2006, 12 courses in the Department of Electrical and Computer Engineering used OASIS. Apart from one small course of 36 students, these courses ranged in size from 100 to 550 students. Each course typically involved two or three lecturers. Additionally, the Department of Physics has adopted OASIS for its year-one courses, involving several hundred further students. While the increase in OASIS usage has been steady rather than spectacular, perhaps because of the large initial time commitment required to create question banks, it is worthy of note that none of the lecturers who adopted OASIS have subsequently stopped using it.

When instructors used OASIS for assessment in their courses, online assessment typically replaced only a small fraction of the traditional assessment, about $10 \%$. In particular, examinations, normally contributing $70 \%$ to the final grade, always remained traditional penand-paper assessments. In spite of this incremental change, instructors were positive about the time saved. They judged that, for course sizes over about 60 students, an OASIS test required less instructor time to set up and mark than a traditional test. Larger courses 
produced considerable savings. For a course of 200 students, the saving was estimated as 50 hours, while for 600 students the saving was approximately 200 hours.

In a minority of courses, OASIS assignments had been introduced in addition to traditional assessments, rather than as replacements. However, instructors in such courses judged that the resultant slightly increased workload brought worthwhile dividends. The first dividend was that both students and instructors received feedback as soon as the students started practicing questions on OASIS. The first OASIS assignment, typically held in the second or third week of the semester, provided further early feedback on student achievement. In traditionally-assessed courses, students and instructors typically received no feedback until the second half of the semester. Worse, this feedback was normally received one or two weeks after the actual assessment on which it was based had taken place.

The second dividend was the increased motivation generated by the online assessment. In fact, interviews with instructors indicated that a number had adopted OASIS in order to lift student motivation and achievement standards, rather than to reduce their workloads. With larger enrollments in courses and a changing student population, instructors had noted over time an increasing reluctance on the part of students to actually work through set questions. Consequently, the achievement of the average student was declining. OASIS was seen as providing a way to motivate students to tackle the work set and improve their skills:

There was a slow tailing off [from a decade ago] to the point where you really couldn't assume that students would do background reading or the questions in the back of the book... I found very quickly that the students weren't really doing the problems... My main motivation for using OASIS is to get students actually working during the course and learning [quote from staff interview].

Instructors judged that OASIS raised student achievement levels and that this improvement persisted from one year to the next. For example, when OASIS practice problems were first provided for one large part of the year-one course, Electrical \& Digital Systems, the examination failure rate for that part (one fifth of the course) dropped from $35 \%$ to $15 \%$. The examination was traditional in nature and the relevant examination questions were, if anything, more demanding than previously. There had not been any significant shift from one year to the next in the ability of the 550 students taking the course. One experienced academic cautioned that examiners needed to guard against unfairly raising the difficulty level of assessments in order to match the increasing student skill levels. Users of other Webbased tutorial systems have made similar observations ${ }^{19}$. It was reported that one instructor, after implementing OASIS in a year-three course taken by 100 students, had replaced a onequestion test with a four-question test and had still achieved better results:

He saw how well the students were doing... his final test, which was in the same amount of time [as previous years], was four of the questions that in previous years he'd only asked one of, and more than $80 \%$ of the students got all four perfectly correct... the test was four times longer and they did three times as well [staff interview].

Lecturers in the Department of Physics also considered that OASIS was well-used and wellliked, and that it had lifted student achievement levels significantly: "Overall positive student feedback and a noticeable improvement in student problem-solving skills in the first full year of OASIS assignments are very encouraging" 34 .

\section{The Student Response to Oasis}


High usage rates for OASIS have been recorded in all courses that provide OASIS practice opportunities. When OASIS was first used in 2002 in the year-one course Electrical \& Digital Systems, the average student submitted answers to 100 questions even though OASIS was provided only for practice that year, along with tutorial and textbook questions. In courses where OASIS is used for assessments, this figure typically increases to around 150 .

The data collected automatically by OASIS show a clear and marked increase in student activity before tests and examinations, strongly confirming the motivating power of assessment. While many academics do believe that there is such an increase in activity, it is difficult to obtain quantitative evidence of such behavior without a data-collection device like OASIS. Figure 4 shows the total number of answers to OASIS questions submitted online by students taking the year-two course Circuits \& Systems prior to their first assessment of the 2006 year, an assignment held in the second week of the semester. A full 50\% of student practice activity for this assessment took place in the last 36 hours ( $8 \mathrm{pm}$ Saturday to $8 \mathrm{am}$ Monday). Ultimately, the average student submitted answers to about 40 questions. It should be noted that this considerable student effort was essentially motivated by an online assignment that required no supervision, no manual marking, and was worth only $2 \%$ of the final grade for the course. Very similar behavior has been repeatedly observed across a range of year levels.

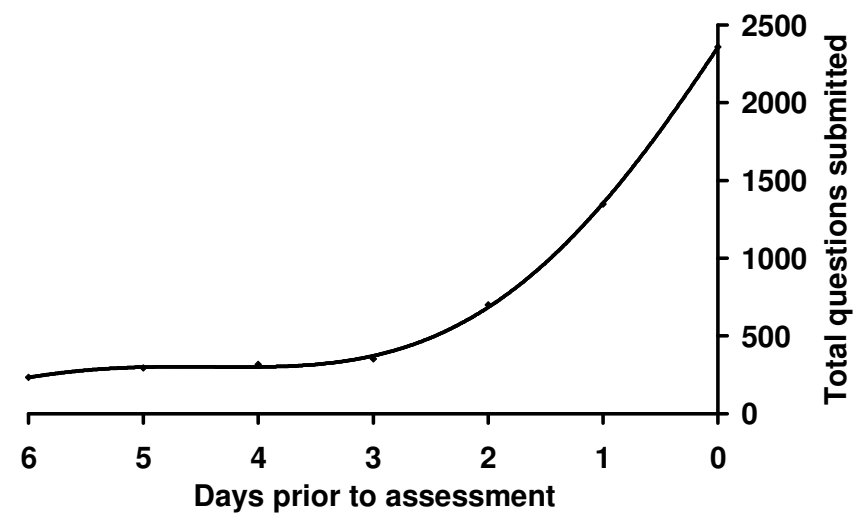

Figure 4: Year-two student activity prior to an assessment.

Students in six courses were surveyed in 2003 and 2004. The survey was in two parts. The first part consisted of ten statements to be rated on a five-point strongly agree to strongly disagree scale. The second part consisted of five open-ended questions designed to allow students to freely express their ideas and opinions about OASIS. Table 1 shows the results for the first part of the 2004 survey of the year-two course Circuits \& Systems, taken by about 200 students. One hundred and twenty-five representative students completed the survey.

The survey results showed that most students (89\%) found OASIS easy to use, while only $2 \%$ did not. The instant feedback was appreciated, with $82 \%$ agreeing or strongly agreeing with the statement, "I like the instant performance feedback using OASIS". Furthermore, 79\% agreed or strongly agreed with the statement, "OASIS helped improve my skill level"; while $83 \%$ agreed or strongly agreed with the statement, "OASIS helps me prepare for the 
assessments". This latter figure was gratifying, since only $10 \%$ of the course assessment had been by OASIS, the remaining $90 \%$ of assessment being traditional (pen and paper).

\begin{tabular}{l|l|l|l|l|l}
\hline Item & $\begin{array}{l}\text { SD } \\
(\boldsymbol{\%})\end{array}$ & $\begin{array}{l}\mathbf{D} \\
(\boldsymbol{\%})\end{array}$ & $\begin{array}{l}\mathbf{N} \\
(\boldsymbol{\%})\end{array}$ & $\begin{array}{l}\mathbf{A} \\
(\boldsymbol{\%})\end{array}$ & $\begin{array}{l}\mathbf{S A} \\
(\%)\end{array}$ \\
\hline OASIS is easy to use & 0 & 2 & 6 & 46 & 43 \\
\hline I often use OASIS & 2 & 13 & 35 & 35 & 14 \\
\hline OASIS helped improve my skill level & 0 & 5 & 14 & 46 & 34 \\
\hline I am more confident about my learning after using OASIS & 0 & 4 & 13 & 54 & 27 \\
\hline OASIS helped me understand the course material better & 0 & 2 & 18 & 50 & 26 \\
\hline OASIS helps me to prepare for the assessments & 1 & 4 & 11 & 50 & 33 \\
\hline I come to campus less often because of OASIS & 15 & 34 & 30 & 8 & 2 \\
\hline I like the instant performance feedback using OASIS & 1 & 1 & 14 & 40 & 42 \\
\hline I prefer to do problems from the text rather than OASIS & 6 & 25 & 46 & 14 & 6 \\
\hline It would be a good idea to have OASIS in other courses & 2 & 2 & 13 & 38 & 40 \\
\hline
\end{tabular}

Table 1: Student evaluation results for OASIS (Key: SD: strongly disagree, D: disagree, N: neutral, A: agree; SA: strongly agree).

The five open-ended questions used in the second part of the survey were:

1. What do you like most about OASIS?

2. What do you like least about OASIS?

3. What changes or improvements would you suggest for OASIS?

4. What benefits do you think students get from using OASIS?

5. Have you any other comments to offer about OASIS?

When asked, "What do you like most about OASIS?" the most frequently mentioned feature by far was the instant feedback. Students also frequently mentioned the large variety of questions, and that questions could be repeated many times with different numerical values. Some students also commented that OASIS helped them improve their skills, perhaps anticipating question four:

"It marks it instantly and there are lots of questions to practice"

"Being able to try problems with different values allows better understanding"

"The chance to sharpen up my basic skills"

"It is a good utility in improving problem-solving skills"

When asked "What do you like least about OASIS?" students most frequently noted that answers are provided without explanation. This issue of OASIS giving answers without explanation was revisited in interviews with students and is discussed later in this section. 
The most common response to the third survey question, "What changes or improvements would you suggest for OASIS?" was a request for more questions and/or topics to be covered. The second most common response was a request for worked solutions to the questions. A few students stated that no changes or improvements were needed: "nothing", "can't get better".

By a considerable margin, the most common replies to the fourth survey question "What benefits do you think students get from using OASIS?" centred on the idea that it provides students with good opportunities to practice problem-solving and to improve skills:

"Improvement to their skills, more understanding"

"Students can keep practicing the same question until they get the hang of the question. And they can practice with different values every time"

"Quite a lot [of benefits] actually. One is from doing a lot of problems. Thinking about the problems for themselves"

Related to this was the idea that students could get feedback about their progress and level of skill and understanding:

"Instant feedback on where they are (what level they are at)"

"They are able to see what concepts they find difficult"

"They can test their understanding of what is being taught in the lectures"

There was little pattern to the responses to the final survey question: "Have you any other comments to offer about OASIS?" The most common response was an encouraging and often fairly general statement to the effect that OASIS was useful and/or good:

"It's a good idea, helps us a lot in many areas of study"

"Sell it, it's a good system. Maybe include a 'how to solve' section"

"Very good way to learn using modern technology"

The surveys produced considerable data about OASIS. However, there was little variation across the surveyed courses in their responses to either the first or the second part of the survey. For example, the percentage of students who agreed or strongly agreed with the statement "OASIS easy to use" was always between $88 \%$ and $92 \%$. In response to the question "What do you like most about OASIS?" the most-frequently mentioned feature was always the instant feedback. Since the picture revealed by the survey appeared relatively stable, it was decided to discontinue the surveys and put research energy into other morerevealing areas, such as student interviews and focus-group discussions.

Over sixty students were formally interviewed on a one-to-one basis about OASIS, while others took part in focus-group discussions. At best, these discussions required little direction, the students finding plenty to discuss and, at times, heatedly debate about OASIS. The interviews and group discussions generally confirmed survey findings and also enabled some of the issues raised by the findings to be examined in greater depth. One such issue was the level of feedback provided. In surveys, a number of students wrote that they would prefer to receive hints or worked solutions, not just the right answer. However, when this issue was raised in focus-group discussions, a sizeable group of students advanced arguments against the provision of worked solutions. First, professional engineers do not receive model answers, or even right answers, to real-world problems. Second, the availability of model 
answers could tempt students to submit a random answer in order to receive the model answer. It was considered that much of the benefit of the exercises was derived from the need to develop skills in choosing the most appropriate problem-solving technique for each exercise:

The reason why I don't like the idea [of hints] is that because one of the cool things about OASIS is that I have learnt is to look at the problem and say - right, I go through it in my head - all the different ways of doing it and looking at it and say, right - I can do it that way. If you have a circuit as an engineer you are not going to have a hint that says - use mesh-current... that's like three-quarters of the game done. Just plug in the numbers and that's done. That's a bit silly.

The exercises also forced students to be very careful with their calculations, since even one minor slip would deny them the right answer. Perseverance was another valuable character trait that the more demanding exercises apparently developed. All these benefits of practice exercises would be diminished if model answers were readily available. Instructors were encouraged that students advanced such arguments themselves, since research indicates that no increased educational value is provided in assistance beyond the correct answer ${ }^{35}$ and that, in fact, too much feedback can be counterproductive ${ }^{36}$.

Students were enthusiastic about OASIS for practice and skills improvement. In particular, they appreciated the instant feedback and that they could repeat questions with different numbers:

I reckon it was really good, though. I phoned a few friends to tell them that I was coming to talk about it and they said, "Yeah, it's an awesome exam resource. It was really good". I actually learnt how to do the problems. Like, there's different levels. You can know how to do it and you can understand why you're doing it, and then you can just do it automatically, if you know what I mean? And it took it from that level of knowing how to do it to understanding why you do the things that you do [student interview].

I thought Oasis was great! Brilliant way of learning - being able to go back and repeat it with different numbers to make sure you understand. I thought it was a really good system! Great way of revising. Don't know that it's such a good way of assessing only because people just get help from others! Unless they were supervised assessments. But yeah, I really enjoyed Oasis [student email].

As the previous student quote suggests, while students were generally enthusiastic about OASIS for practice and skills improvement, their opinions about OASIS assignments were mixed. These student opinions led to OASIS assessment practices being repeatedly modified over a number of cycles of the action-research program. Some students considered that assignments were unfair because their unsupervised nature allowed cheating. Initially, assignments were based on previously-seen questions. Students often prepared for these assignments by writing out methods for each practice question. Instructors were happy with this. However, some students prepared spreadsheets and offered them to others: students who did not prepare for the assignments could still score well by using such a spreadsheet. In order to counteract spreadsheets, extra OASIS questions used only in assignments were written. Although some academics wondered if OASIS was promoting rote rather than deep learning, the move to previously-unseen questions similar to the practice questions did not result in a significant drop in assignment marks, perhaps indicating that most students were in fact making an effort to understand how to do the practice questions. 
Even after this change, a number of students still expressed dissatisfaction with OASIS assignments, reporting that some students watched their peers sitting the assignment in the morning, noted the questions that were in the assignment, practiced those questions, and then, suitably prepared, sat the assignment themselves later in the day:

Just walk into the level-three computer labs on the day of an assessment and you'll see hordes of first-year losers (myself included) crowded around a single computer, busily copying the test questions, memorizing the solutions, giving/receiving/demanding excessive help [student email].

Interestingly, the data collected by OASIS showed that students who sat the assignment earlier in the day tended to score more highly than those who sat it later. However, in order to make the assignments seem as fair as possible, assignments in which different students received different questions were implemented. It was judged that this would make it virtually impossible for students to learn which questions were in the assignment by watching their peers sit the assignment: the total number of questions involved was just too large. This move to alternative questions actually made little difference to overall results. Table 2 illustrates the average marks over a three-year period for the two OASIS assignments in the year-one course 'Electrical and Digital Systems' taken by over 550 students. There was little variation in the averages over the three years even though in 2003 the assignments were based purely on questions the students had previously seen and practiced, in 2004 previouslyunseen questions were used, and in 2005 both previously-unseen questions and alternative questions were used. The somewhat lower average mark in the first assignment of 2004 is attributed to university network problems which effectively reduced the length of time students had for the assignment.

\begin{tabular}{|l|l|l|l|}
\hline Assignment & $\mathbf{2 0 0 3}$ & $\mathbf{2 0 0 4}$ & $\mathbf{2 0 0 5}$ \\
\hline First assignment & $82 \%$ & $75 \%$ & $80 \%$ \\
\hline Second assignment & $92 \%$ & $88 \%$ & $88 \%$ \\
\hline
\end{tabular}

Table 2: OASIS Assignment average marks in the year-one course 'Electrical and Digital Systems'

It was clear that students did often group together for OASIS assignments. Given the individualized nature of assignments, this often required the students in a group to do the assignment three or four times. Instructors were generally accepting of group-work approaches to assignments because they considered that an adequate level of learning was taking place in such situations. Some students saw it in the same light, while others saw it as cheating:

I have a lot of engineering friends and during OASIS time they just work as a group, everybody do one person's assignment, everybody calculate at the same time and they just put the answers which have the same answers so everyone got good marks apart from me... it's not fair [student interview].

We did the practices before so when we do the actual assignment it only took us about 20 minutes. So we actually have 40 minutes more. As for me I have two team members so I 
spend 20 minutes checking for his. I redo everything. I spend 20 minutes and I redo everything. I spend another 20 minutes on another person. So they did the same too, like there's three of us in a team, so we help each other out... Engineering is actually about team spirit and about team work... OASIS indirectly actually instils something about team spirit [student interview].

The only thing I thought a bit flawed about OASIS was that it was easy for friends to get together and help each other out. I am guilty of this, but I also found this group-work was ideal for learning. So ultimately, I found OASIS was a real help for my learning [student email].

While instructors were generally accepting of group-work approaches to assignments, there was some unease about the possibility of students simply getting others to do their assignments, even though, based on student feedback, this did not seem to be a widespread problem. To counter this possibility, a rule that had been suggested by students in a focusgroup discussion was therefore introduced. This rule ensured that the OASIS assignment marks could not lift the overall course mark by more than $3 \%$ for any student.

\section{Conclusion and future developments}

The present version of the OASIS software package has been successfully used in over a dozen courses in the Department of Electrical and Computer Engineering since the start of 2003 , with a prototype version used prior to that. There are 200 to 300 numerical versions of each question, allowing great opportunities for repetition, facilitating student skills practice and development and making assessment more secure against cheating. Assessments can also be further individualized, with different students receiving different questions. Consequential marking for multi-part questions and repeat attempts for partial credit can also be implemented in assessments to make the process fairer and more student-friendly.

Data gathered over a four-year period from surveys, interviews, focus-group discussions, emails and informal communications with both present and past students indicate clearly that students regard OASIS as a valuable learning tool. They find it easy to use, use it often, and judge that it helps them lift their skill and understanding levels. While the motivational aspects of OASIS assessments are appreciated, some students consider that OASIS assignments are unfair because students can rely too much on the efforts of others. A series of steps has been taken to reduce this perception, with previously-unseen questions, different questions for different students, and a restriction on the extent to which OASIS marks can boost final course marks all being implemented.

OASIS has enabled instructors to maintain effective teaching and assessment practices as student enrollments in courses increase. The initial aim in introducing OASIS was staff workload reduction: traditional assessments could be replaced by online assessments that were marked automatically. However, interviews with instructors who used OASIS revealed that the majority viewed it as a way to enhance student learning rather than to reduce instructor workloads. In a minority of cases online assessments had even been added to courses while no traditional assessments had been removed. The student-performance feedback provided to instructors enabled them to offer timely assistance to poorly-performing students, to target concepts and questions that present students with particular difficulties, and to improve course delivery in an informed fashion. Instructors spoke enthusiastically about OASIS in interviews, and all instructors using OASIS were positive that it had raised student achievement levels significantly. In some cases this had led to instructors increasing the 
difficulty of their assessments. None of the instructors who had adopted OASIS had subsequently stopped using it.

OASIS remains a work-in-progress. An OASIS question-composer has recently been produced in order to make it easier for instructors to produce questions for OASIS. This question-composer is being extended to handle questions that involve Boolean algebra and a range of number bases. An "AJAX"-based diagram editor will also be added to the questioncomposer. Once these additions have been implemented successfully, the intention is to make OASIS available as open-source software.

Research based on OASIS is also ongoing. Instructors are now compiling concept inventories to be delivered and marked by OASIS. Such course concept inventories will make it possible to track the level of student understanding through a course and to identify common student misconceptions, thus informing improvements to course design.

\section{References}

1. Hale, S.E., Report of the committee on university teaching method. 1964, HMSO: London.

2. Robbins, L., Higher education. 1963, HMSO: London.

3. Dill, D.D. and B. Sporn, The implications of a postindustrial environment for the university: An introduction, in Emerging patterns of social demand and university reform: Through a glass darkly, D.D. Dill and B. Sporn, Editors. 1995, Pergamon: Oxford. p. 1-19.

4. Sporn, B., Adaptive university structures: An analysis of adaptation to socioeconomic environments of US and European universities. 1999, London: Jessica Kingsley.

5. Excell, P.S., Experiments in the use of multiple-choice examinations for electromagnetics-related topics. IEEE Transactions on Education, 2000. 43(3): p. 250-256.

6. Innis, K., Diary survey: how undergraduate full-time students spend their time. 1996, Leeds: Leeds Metropolitan University.

7. Miller, C.M.L. and M. Parlett, Up to the mark: A study of the examination game. 1974, Guildford, UK: Society for Research into Higher Education.

8. $\quad$ Snyder, B.R., The hidden curriculum. 1971, New York: Knopf.

9. Freilich, M.B., A student evaluation of teaching techniques, in Teaching engineering: A beginner's guide, M.S. Gupta, Editor. 1987, IEEE Press: New York.

10. Gibbs, G., Using assessment strategically to change the way students learn, in Assessment matters in higher education: choosing and using diverse approaches, S. Brown and A. Glasner, Editors. 1999, The Society for Research into Higher Education \& Open University Press: Buckingham, UK \& Philadelphia, PA. p. 41-53.

11. Mehta, S.I. and N.W. Schlecht, Computerized assessment technique for large classes. Journal of Engineering Education, 1998. 87(2): p. 167-172.

12. Black, P. and D. Wiliam, Inside the black box: raising standards through classroom assessment. Phi Delta Kappan, 1998. 80(2): p. 139-148.

13. Zakrzewski, S. and J. Bull, The mass implementation and evaluation of computer-based assessments. Assessment \& Evaluation in Higher Education, 1998. 23(2): p. 141-152.

14. Deeks, A. Web-based assignments in structural analysis. in Australasian Association for Engineering Education 11th Annual Conference. 1999. Adelaide, Australia: University of South Australia.

15. Reinhardt, A., New ways to learn, in Byte, The Magazine of Technology Integration. 1995. p. 50-72.

16. Bull, J. and C. McKenna, Blueprint for computer-assisted assessment. 2004, London: RoutledgeFalmer.

17. Sly, L., Practice tests as formative assessment improve student performance on computer-managed learning assessments. Assessment \& Evaluation in Higher Education, 1999. 24(3): p. 339-343.

18. Sly, L. and L. Rennie, Computer managed learning as an aid to formative assessment in higher education, in Computer-assisted assessment in higher education, S. Brown, P. Race, and J. Bull, Editors. 1999, Kogan Page: London. p. 113-120. 
19. Scott, N.W. and B.J. Stone, A flexible web-based tutorial system for engineering, maths and science subjects. Global Journal of Engineering Education, 1998. 2(1): p. 7-16.

20. Scott, N.W. and B.J. Stone, We did it our way (and you must do it your way). Australasian Journal of Engineering Education, 1999. 8(2): p. 99-123.

21. Kashy, D.A., et al., Teaching with ALN technology: benefits and costs. Journal of Engineering Education, 2001. 90(4): p. 499-505.

22. Thoennessen, M. and M.J. Harrison, Computer-assisted assignments in a large physics class. Computers and Education, 1996. 27(2): p. 141-147.

23. Cohen, L., L. Manion, and K. Morrison, Research methods in education. 2000, London: Routledge Falmer.

24. Bassey, M., Action research for improving educational practice, in Teacher research and school improvement: Opening doors from the inside, R. Halsall, Editor. 1998, Open University Press: Buckingham. p. 93-108.

25. Dick, B. Action research: action and research. 2002 [cited; Available from: http://www.scu.edu.au/schools/gcm/ar/arp/aandr.html.

26. Elliott, J., Action research for educational change. 1991, Philadelphia, PA: Open University Press.

27. Carr, W. and S. Kemmis, Becoming critical: education, knowledge and action research. 1986, Lewes, UK: Falmer.

28. Zuber-Skerritt, O., Introduction, in New directions in action research, O. Zuber-Skerritt, Editor. 1996, Falmer Press: London. p. 3-9.

29. Ary, D., L.C. Jacobs, and A. Razavieh, Introduction to research in education. 2002, Belmont, CA: Wadsworth/Thomson Learning.

30. Gall, M.D., W.R. Borg, and J.P. Gall, Educational research: An introduction. 1996, White Plains, NY: Longman.

31. Wragg, E.C., An introduction to classroom observation. 1994, London: Routledge.

32. N6. 2007 [cited; Available from: http://www.qsrinternational.com/products/productoverview/N6.htm.

33. Russell, M., A. Goldberg, and K. O'Connor, Computer-based testing and validity: a look back into the future. Assessment in Education, 2003. 10(3): p. 279-293.

34. Kruhlak, R., et al. Online Practice and Assessment in First Year Physics. in Canadian Association of Physicists Congress. 2005. Vancouver, Canada.

35. Gordijn, J. and W. Nijhof, Effects of complex feedback on computer-assisted modular instruction. Computers and Education, 2002. 39(2): p. 183-200.

36. Chen, P.M., An automated feedback system for computer organization projects. IEEE Transactions on Education, 2004. 47(2): p. 232-240. 